\title{
The Effects of Using Seaweed on the Quality of Asian Noodles
}

\section{Xiren Guli Keyimu*}

Faculty of chemical science and food technology, University of kabangsaan, Malaysia

\begin{abstract}
Seaweeds contain high levels of minerals, vitamins, essential amino acids, indigestible carbohydrates, and dietary fiber. The objective of this study was to use Gracilaria seaweed powder as an ingredient to make Alkaline noodle products of high nutritional quality with rich fiber content. The effect of wheat flour substitution with Gracilaria seaweed powder was investigated in terms of the physicochemical, textural and sensory qualities of Asian Alkaline noodles. Five additional noodles were prepared by substituting wheat with $0,1,3,5$ and $7 \%$ Gracilaria seaweed powder. The optimal ratio of noodle from Gracilaria seaweed powder was investigated using sensory qualities in comparison with the control $(100 \%$ wheat flour). The result of noodle formula development indicated that as the amount of Gracilaria seaweed powder increased, the stickiness of the noodles decreased and the appearance became darker. The optimum seaweed noodle formulation consisted of 3: 97\% seaweed powder and wheat flour ratio, $32 \%$ water, $1 \%$ salt, $1 \%$ kansui. The seaweed noodles containing $3 \%$ Gracilaria were composed of $7.21 \%$ protein, $0.5 \%$ fat, $1.7 \%$ dietary fiber, $1.05 \%$ ash, $40.15 \%$ moisture. The results of consumer evaluation showed that the overall liking of seaweed noodles were at the moderate level. The present study indicated that Gracilaria seaweed is a potential source of fiber when substituted for wheat flour in noodle products. The incorporation of $3 \%$ Gracilaria seaweed in the noodle ingredients significantly increased their total dietary fiber content.
\end{abstract}

Keywords: Alkaline noodles; Gracilaria seaweed

\section{Introduction}

Noodles came to China as early as 5000 BC, and then spread to other Asian countries such as Japan, Thailand, Korea and Malaysia, it has become one of the fastest growing sectors in the world with the compound annual growth rate (CAGR) reaching 4\% [1]. Noodles are one of the favorite food products that are well loved by many people of all ages. It has been a popular food item due to their convenience of preparation and reasonable price. They are readily adjustable to the local diet, easy to prepare, highly suitable and an all time favorite of almost everybody. Noodles is commonly made from simple flour and is enriched with nutrients and minerals needed by the body [2]. Noodles is known as a staple food in Malaysia but some nutritional components such as carotene, higher concentration of fiber and mineral are considered low or insufficient. Therefore, incorporation of seaweed in noodles gives extra properties that are high in fiber and indirectly contributes to the minerals content. This study is to diversify the usage of seaweed by incorporating it in noodles. It would also increase the variety of healthy food in Malaysia.

Seaweeds are valued marine plants, the multifaceted uses of these plants in food, chemical and textile industries, agriculture, pharmaceuticals and medicine have been well recognized [3]. Seaweeds have become a major food ingredient in products especially in Japan, Korea and China. Ismail et al. [4] reported that most Europeans and Americans use processed seaweeds as additives in their food preparation. In Asia, seaweeds have been used for centuries in the preparation of salads, soups and also as low-calorie foods. Although most Malaysians exhibit little interest in consuming seaweeds, it is consumed by small volumes of the population along the coastal areas of Peninsular Malaysia and East Malaysia [4].

Gracilaria grows profusely in the mangroves fringing the west coast of Malaysia [5]. Gracilaria seaweed when used as food provides substantial amounts of fiber, minerals, lipids and protein, vitamins and mineral essential for human nutrition [6]. More importantly, this tropical seaweed produces agar and agarose with high gel strengths [5], and is a potential resource for industrial development in Malaysia.
Information on the genetics of Gracilaria is therefore important for better utilization of this seaweed [7]. Gracilaria is a potential health food in human diets and use to the food industry as a source of ingredients with high nutritional value. Gracilaria can afford a dietary substitute due to its nutritional importance and its commercial value can be enhanced by improving the quality and increasing the range of seaweed-based products [6].

\section{Materials and Methods}

\section{Sampling of seaweed}

Gracilaria Seaweed was collected from Sabah, Malaysia. The seaweed was cleaned, washed with distilled water to remove epiphytes and encrusting material and then freeze-dried; dry seaweed powder samples were stored in plastic bags in desiccators at room temperature prior to extraction [8]. After preparation of Gracilaria seaweed powder, all noodle ingredients: $50 \mathrm{~g}$ flour, $16 \mathrm{~g}$ water, $0.5 \mathrm{~g}$ Kansui and $0.5 \mathrm{~g}$ salt were prepared.

\section{Materials and processing}

Noodles were prepared in the laboratory. The basic ingredients used for making noodles were: $50 \mathrm{~g}$ flour, $16 \mathrm{~g}$ water, $0.5 \mathrm{~g}$ salt, $0.5 \mathrm{~g}$ kansui. Control dried noodles were prepared from $100 \%$ wheat flour. Four additional noodle samples were prepared by substituting wheat with $1 \%, 3 \%, 5 \%$ and $7 \%$ Gracilaria seaweed powder.

Alkaline salt was dissolved in a appropriate amount of deionized

*Corresponding author: Xiren Guli Keyimu, Faculty of chemical science and food technology, University of kabangsaan, Malaysia, E-mail: xiren.guli@yahoo.com

Received December 17, 2012; Accepted January 17, 2013; Published January 25, 2013

Citation: Keyimu XG (2013) The Effects of Using Seaweed on the Quality of Asian Noodles. J Food Process Technol 4: 216. doi:10.4172/2157-7110.1000216

Copyright: (c) 2013 Keyimu XG. This is an open-access article distributed under the terms of the Creative Commons Attribution License, which permits unrestricted use, distribution, and reproduction in any medium, provided the original author and source are credited. 
water before addition to flour. The solution was stirred constantly using magnetic stirrers in $500 \mathrm{ml}$ plastic screw cap containers until all salt (or alkali) was dissolved. Flour sample and seaweed powder was measured and placed in the mixer bowl of mixer and the mixed for 30 sec. Using a rubber spatula a well was made in the center of the bowl and all the alkaline salt solution was added. Total mixing time was 3 min and $30 \mathrm{sec}$ after rested for 30 minutes (1st resting).

The dough was compounded using the rolls of a noodle machine. The gap on the rollers was set at $4.0 \mathrm{~mm}$ and the dough crumble was compressed between them to form the first crude sheet. The dough was resheeted 3 more times, each time being folded once and traveling through the rollers in the same direction. The dough sheet was placed loosely, the dough sheet was rested for another 30 minutes (2nd resting).

After the 2nd rest, the dough was sheeted by passing it through the rollers 4 times with progressively reduced gaps of 3.5, 3.0, 2.0 and $1.5 \mathrm{~mm}$. The roll gap was adjusted accordingly to give a final dough thickness of $1.2 \pm 0.05 \mathrm{~mm}$. From the dough sheet, a $4 \mathrm{~cm}$ section was cut off for noodle dough and the dough sheet was cut into strips with a $\# 12$ square type cutter ( $2.5 \mathrm{~mm}$ width). All the noodle dough and strip samples were stored at room temperature for $24 \mathrm{~h}$ before cooking.

\section{Noodle cooking}

Seaweed noodles were measured and set aside. $750 \mathrm{ml}$ of distilled water was boiled in stainless steel pots until boiling rapidly. The noodles were added and boiled at high heat for $1 \mathrm{~min}$, after $1 \mathrm{~min}$, temperature was lowered to medium, to stop water from boiling over. Cooking then continued for another 5 minutes until the uncooked core has disappeared. The total cooking time was 6 minutes. After cooking, the noodle sample was rinsed with distilled water at room temperature $\left(20.7-21.5^{\circ} \mathrm{C}\right)$ for 1 minute. The noodles were then ready for texture measurements.

\section{Proximate analysis}

The chemical proximate compositions of Gracilaria and Ulva seaweed noodle samples were determined as follows:

The moisture content was determined by gravimetric heating $\left(130^{\circ} \mathrm{C}\right.$ for $\left.8 \mathrm{~h}\right)$ using a $2-3 \mathrm{~g}$ sample. Ash and protein were analyzed according to American Association of Cereal Chemists methods 0801 and 46-13, respectively (AACC, 2000). Total dietary fiber (DF) was evaluated using Official Methods of Analysis 985.29 (AOAC, 1999). All analyses were performed in triplicate.

\section{Determination of color}

Seaweed noodle color quality requirement is brown. This depends on the quantity of seaweed content. The noodle color will be measured by using color meter (L. a. b system). The $L^{\star}$ (brightness or whiteness), $a^{*}$ (redness and greenness), and $b^{*}$ (yellowness and blueness) values were determined [9].

\section{Texture analysis (Shimadzu AGS-j 500n)}

A texture analyzer (Shimadzu AGS-J 500N) equipped with a texture analyzer software was used to measure noodle hardness of seaweed noodles by the method of Mastication test, cross head speed of $50 \mathrm{~mm} / \mathrm{min}$ and depth of $3 \mathrm{~mm}$. The average of three replicates was reported in Newtons $(\mathrm{N})$.

\section{Sensory evaluation}

Noodle samples were arranged for sensory evaluation. The samples were then stored for not more than $30 \mathrm{~min}$ in tightly covered plastic food containers before testing. Optimally cooked noodles with soup were evaluated for appearance, flavor, taste, texture and overall liking of the samples by 30 untrained panelists using nine-point hedonic scales, where $9=$ =xtremely like and $1=$ extremely dislike. Each panelist evaluated six samples (identified by unique three-digit codes) in a balanced sequential order. The optimal ratio of Gracilaria seaweed in the noodles was investigated using sensory qualities in comparison to the control noodles [10].

\section{Statistical analysis}

The means and standard deviations were determined for all the physicochemical, textural, cooking and sensory qualities studied. The significant difference of mean values was assessed with one-way analysis of variance (ANOVA) followed by Duncan's test using SPSS software at a significance level of $(P<0.05)[10]$.

\section{Results and Discussion}

\section{Proximate analysis of seaweed noodles}

Table 1 show the proximate compositions of Gracilaria seaweed noodles, also includes the proximate compositions of the noodles prepared with different level of Gracilaria powder. The results show that while the level of incorporated Gracilaria powder increases, there is a relative decrease in the moisture content of Gracilaria seaweed noodles. When seaweed addition level is $0 \%$, the value of moisture is $41.96 \%$. While at seaweed addition level is $7 \%$, the moisture of noodle decreased $36.46 \%$. This might be due to high levels of seaweed powders which increases the water absorption. This pattern is related to the decrease in the protein content with the increase in the amount of seaweed powder in the noodle where the network produced by the gluten is reduced [10].

As shown in table 1, the ash, fiber, protein, moisture and fat content of seaweed noodles was significant difference with variation of seaweed content $(\mathrm{p}<0.05)$. Ash and fiber content increased when the seaweed powder amount increased in the noodles. The control sample showed the lowest value of ash $0.56 \%$, fiber $1.40 \%$, while the noodles containing $7 \%$ Gracilaria seaweed powder had the highest values of ash $1.19 \%$ and fiber $1.76 \%$.

Matanjun et al. [11] reported that Gracilaria seaweed has 37.15\%

\begin{tabular}{|l|c|c|c|c|}
\hline Sample & Moisture & Ash & Protein & Fat \\
\hline control & $41.96 \pm 0.04 \mathrm{a}$ & $0.56 \pm 0.08 \mathrm{e}$ & $7.32 \pm 0.06 \mathrm{a}$ & $0.29 \pm 0.00 \mathrm{e}$ \\
\hline $1 \%$ & $41.49 \pm 0.02 \mathrm{~b}$ & $1.02 \pm 0.08 \mathrm{~d}$ & $7.26 \pm 0.03 \mathrm{~b}$ & $0.59 \pm 0.01 \mathrm{a}$ \\
\hline $3 \%$ & $40.15 \pm 0.05 \mathrm{c}$ & $1.05 \pm 0.03 \mathrm{c}$ & $7.21 \pm 0.02 \mathrm{c}$ & $0.50 \pm 0.04 \mathrm{~b}$ \\
\hline $5 \%$ & $38.56 \pm 0.01 \mathrm{~d}$ & $1.09 \pm 0.08 \mathrm{~b}$ & $6.93 \pm 0.00 \mathrm{~d}$ & $1.55 \pm 0.05 f$ \\
\hline $7 \%$ & $36.46 \pm 0.01 \mathrm{e}$ & $1.19 \pm 0.04 \mathrm{a}$ & $6.49 \pm 0.06 \mathrm{e}$ & $0.37 \pm 0.00 \mathrm{c}$ \\
\hline
\end{tabular}

Means in the same column with different superscripts are different $(p<0.05)$. 
ash and $25.05 \%$ fiber content. Thus, the intake of the composite noodles might contribute to the satisfy ash and fiber requirements [12].

\section{Color characteristics}

Table 2 shows the color characteristic of seaweed noodles at different concentration of seaweed content. The results show apparent differences in chromameter values among the noodle samples.

The $L$ values of noodle color significantly $(\mathrm{p}<0.05)$ decreased as Gracilaria seaweed powder level increased, which indicates a decrease in the noodle brightness. As the amount of seaweed increased from 0 to $7 \%$, the color become significantly darker which indicated by decreasing of $\mathrm{L}^{*}$ values. Due to the hygroscopic property of seaweed, it might absorb much water and lowered the moisture content, low moisture content cause darker color [13]. Moreover, there was significantly higher intensity of redness by increasing seaweed content which was indicated by increasing in $\mathrm{a}^{\star}$ values $(\mathrm{p}<0.05)$.

\section{Noodle texture analysis}

The hardness of the noodles was measured. The addition of seaweed powder and juice increased the hardness of the noodles sample, the increasing value of noodle hardness might have been due to the water absorbing property of seaweed. These results indicated that the decrease which was recorded at 0 and $1 \%$ seaweed addition level did not create enough effect on moisture activity at $32 \%$ moisture level. As the seaweed addition level was increased to $3.0 \%$, viscoelastic development arising from moisture-seaweed interaction was created. This led to a more pronounced activity of seaweed over moisture thereby causing an increase in hardness, as the added seaweed quantity was increased to $7.0 \%$, the effect of seaweed became more pronounced, which is leading to an increase in the value of hardness [14] (Figure 1).

\section{Sensory evaluation}

Consumers normally purchase noodle products daily from either convenience stores or local manufacturers. Their purchasing decisions are based upon their initial assessment of noodle quality by its visual appearance such as color, brightness and the absence of undesirable specks [15]. In the present study, the sensory evaluation of optimally cooked noodles which supplemented with seaweed powder was carried out with the objective to select the best suited seaweed (by percentage) for the preparation of the noodles. The sensory liking scores for

\begin{tabular}{|l|c|c|c|}
\hline Sample & $\mathbf{L}^{*}$ & $\mathbf{a}^{*}$ & $\mathbf{b}^{*}$ \\
\hline control & $60.64^{\mathrm{b}}$ & $-2.90^{\mathrm{e}}$ & $22.52^{\mathrm{a}}$ \\
\hline $1 \%$ & $53.23^{\mathrm{b}}$ & $-0.06^{\mathrm{d}}$ & $17.81^{\mathrm{b}}$ \\
\hline $3 \%$ & $51.39^{\mathrm{c}}$ & $1.32^{\mathrm{c}}$ & $13.61^{\mathrm{c}}$ \\
\hline $5 \%$ & $50.80^{\mathrm{d}}$ & $2.35^{\mathrm{b}}$ & $9.62^{\mathrm{e}}$ \\
\hline $7 \%$ & $48.47^{\mathrm{e}}$ & $2.65^{\mathrm{a}}$ & $11.50^{\mathrm{d}}$ \\
\hline
\end{tabular}

Means in the same column with different superscripts are different $(p<0.05)$

$\mathrm{L}^{*}=$ lightness $(0=$ black, $100=$ white $)$

$\mathrm{a}^{*}=$ redness $/$ greenness $(+=$ red,$-=$ green $)$

$\mathrm{b}^{*}=$ yellowness/blueness $(+=$ yellow, $-=$ blue $)$

Table 2: Color characteristics of seaweed noodles.

\begin{tabular}{|l|l|l|l|l|l|}
\hline $\begin{array}{l}\text { Seaweed } \\
\text { content }\end{array}$ & Appearance & Flavor & Taste & Texture & $\begin{array}{l}\text { Overall } \\
\text { acceptance }\end{array}$ \\
\hline $1 \%$ & $6.5^{\mathrm{a}}$ & $6.4^{\mathrm{a}}$ & $6.1^{\mathrm{a}}$ & $6.4^{\mathrm{a}}$ & $6.5^{\mathrm{a}}$ \\
\hline $3 \%$ & $6.2^{\mathrm{b}}$ & $5.7^{\mathrm{b}}$ & $5.0^{\mathrm{b}}$ & $5.0^{\mathrm{b}}$ & $6.2^{\mathrm{b}}$ \\
\hline $5 \%$ & $4.9^{\mathrm{c}}$ & $3.8^{\mathrm{c}}$ & $3.5^{\mathrm{c}}$ & $3.7^{\mathrm{c}}$ & $4.0^{\mathrm{c}}$ \\
\hline $7 \%$ & $3.0^{\mathrm{d}}$ & $3.0^{\mathrm{d}}$ & $2.7^{\mathrm{d}}$ & $2.2^{\mathrm{d}}$ & $2.8^{\mathrm{d}}$ \\
\hline
\end{tabular}

Table 3: Eating qualities of seaweed noodles.

\section{hardness}

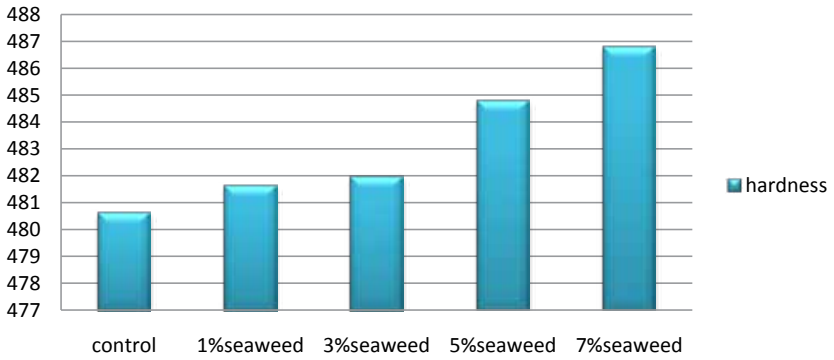

Figure 1: Texture characteristics (hardness) of noodles supplemented with Gracilaria seaweed.

appearance, flavor, taste, texture and overall liking of optimally cooked noodles supplemented with seaweed are shown in table 3 .

Mean in the same column with different letters differ significantly ( $p<0.05$ ) by Duncan's multiple range test. Scale of $1-9$, the control sample is scored 7 for each item.

The sensory analysis for hedonic tests were conducted by 30 consumer panels. Five sensory attributes namely, appearance, flavor, taste, texture and overall acceptability were evaluated. The results of the sensory evaluation of seaweed noodles prepared with Gracilaria seaweed powder and juice, Ulva seaweed powder and juice are listed in table 3.

In terms of appearance characteristics, noodles containing $1 \%$ Gracilaria powder had the highest score for appearance, while containing 3\% Gracilaria powder noodles had higher score for appearance attribute respectively. Meanwhile, noodles made from 7\% Gracilaria powder noodles obtained the lowest score for colour property.

In relation to flavor attribute, the most desirable flavor was attributed to noodles containing $1 \%$ Gracilaria seaweed powder with the best score of 6.40 .

The taste attributes of the noodles made from $1 \%$ Gracilaria seaweed noodles recorded highest results with mean scores of 6.10 . On the other hand, containing $7 \%$ Gracilaria seaweed noodles had the lowest score for taste. For texture, noodles containing 1\% Gracilaria seaweed had the highest score and 7\% Gracilaria powder had the lowest texture score. With the respect to overall acceptability, the most preferred noodles were that of containing $1 \%$ and $3 \%$ Gracilaria seaweed noodles. While, containing 7\% Gracilaria seaweed noodles had the lowest score for overall acceptability attribute.

All sensory attributes of Gracilaria seaweed noodles that served as the $1 \%$ were significantly the highest $(\mathrm{p}<0.05)$ among all samples. The 7\% Gracilaria seaweed noodles showed the lowest score among all samples in all sensory attributes. The more Gracilaria seaweed powder was added to the noodles, the less acceptable the noodles were to the panelists. The increase in Gracilaria powder might have contributed a dark color and less elastic texture. These characteristics might not have been favorable to the panelists.

\section{Conclusion}

Gracilaria seaweed could be added to Alkaline noodles up to the level of $3 \%$ without any significant change in organoleptic 
Citation: Keyimu XG (2013) The Effects of Using Seaweed on the Quality of Asian Noodles. J Food Process Technol 4: 216. doi:10.4172/21577110.1000216

characteristics. Noodles made from 3\% Gracilaria seaweed were considered as most acceptable organoleptically and nutritionally as they contained appreciable amounts of fiber $1.7 \%$ and ash $1.05 \%$. The development of such functional status of the general population but also helps those suffering from degenerative diseases associated with today's changing life styles and environment.

\section{References}

1. Lee CH, Cho JK, Lee SJ, Koh WB, Park WJ, Kim CH (2002) Enhancing $\beta$ Carotene Content in Asian Noodles by Adding Pumpkin Powder. Cereal Chem 79: $593-595$

2. Afalla A (2010) Nutria-enriched seaweed noodles. Aquatic Technology Competion and Marketplace 70-77.

3. Dhargalkar VK, Kavlekar D (2004) Seaweeds - a field manual. National Institute of Oceanography, Dona Paula, Goa - 403004 .

4. Ismail A, Tan S (2002) Antioxidant activity of selected commercial seaweeds Malays J Nutr 8: 167-177.

5. Phang SM, Shaharuddin S, Noraishah H, Sasekumar A (1996) Studies on Gracilaria changii (Gracilariales, Rhodophyta) from Malaysian mangroves. Hydrobiologia 327: 347-352.

6. Norziah MH, Ching CY (2000) Nutritional composition of edible seaweed Gracilaria changgi. Food Chemistry 68: 69-76.

7. Chung C, Hwang RL, Lin SH, Wu TM, Wu JY, et al. (2007) Nutrients, temperature, and salinity as primary factors influencing the temporal dynamics of macroalgal abundance and assemblage structure on a reef of Du- Lang Bay in Taitung in southeastern Taiwan. Botanical Studies 48: 419-433.

8. Sasidharan S, Darah I, Noordin MK (2008) Preliminary isolation and in vitro antiyeast activity of active fraction from crude extract of Gracilaria changii. Indian J Pharmacol 40: 227-229.

9. Guo G, Jackson DS, Graybosch RA, Parkhurst AM (2003) Asian Salted Noodle Quality: Impact of Amylose Content Adjustments Using Waxy Wheat Flour. Cereal Chem 80: 437-445.

10. Ritthiruangdej P, Parnbankled S, Donchedee S, Wongsagonsup R (2011) Physical, Chemical, Textural and Sensory Properties of Dried Wheat Noodles Supplemented with Unripe Banana Flour. Kasetsart J (Nat Sci) 45: 500 - 509.

11. Matanjun $P$, Teng CP, Ismail NB, Kassim MIAB, Yi CW, et al. (2011) Nutrient Composition and Antioxidant Activities of Several Malaysian Tropical Seaweeds. The 12th ASEAN Food Conference 2011, Bangkok, Thailand.

12. Apaydın G, Aylıkcı1 V, Cengiz E, Saydam M, Küp N, Tıraşoğlu E (2010) Analysis of Metal Contents of Seaweed (Ulva lactuca) from Istanbul, Turkey by EDXRF. Turkish Journal of Fisheries and Aquatic Sciences 10: 215-220.

13. Chin CK, Huda N, Yang TA (2012) Incorporation of surimi powder in wet yellow noodles and its effects on the physicochemical and sensory properties. International Food Research Journal 19: 701-707.

14. Abd El-Baky HH, Baz FK, Baroty L (2008) Evaluation of Marine Alga Ulva lactuca $\mathrm{L}$. as A Source of Natural Preservative Ingredient. American-Eurasian J Agric Environ Sci 3: 434-444.

15. Ekthamasut K (2006) Effect of Tomato Seed Meal on Wheat Pasting Properties and Alkaline Noodle Qualities. AU JT 9: 147-152. 